\title{
Accelerator Mass Spectrometry (AMS) in Radioecology
}

\author{
M. García-León* \\ Universidad de Sevilla \\ Centro Nacional de Aceleradores \\ Avda. T. A. Edison \\ 41092 Sevilla \\ Spain
}

\begin{abstract}
Accelerator Mass Spectrometry (AMS) provides with an excellent sensitivity for the determination of radionuclides in the environment. In fact, conventional radiometric techniques can hardly compete with AMS in the solution of many problems involving the measurement of very low levels of radioactivity in Nature. For that reason, during the last years AMS has become a powerful tool for Radioecology studies.

In this paper a review is done on the evolution of AMS applications to the measurement of environmental radioactivity and, therefore, its contribution to the understanding of radionuclide behavior in Nature.For that, the advantages of using AMS to determine key nuclides as ${ }^{129} \mathrm{I},{ }^{14} \mathrm{C}$, Pu-isotopes and others in different natural compartments will be discussed. The content of the paper is illustrated with the contributions to these studies of the Spanish National Center for Accelerators (CNA) AMS systems.
\end{abstract}

\section{Introduction}

One of the main interest in Radioecology is the study of the dynamics and behaviour of radionuclides in the environment, their sources and fate. For that we need to measure radioactivity in Nature. In the majority of the cases at low or very low levels. Radiometric methods solve this problem by the direct mesurement of the radiations emitted by the radionuclides as a way of determining its activity. The basis for these methods is the well known Equation.

$$
A=\lambda N
$$

Being A the activity of the sample, $\lambda$ the disintegration constant and $\mathrm{N}$ the number of radioactive nuclei. There are many examples in the literature which show how these methods have succeeded all along the history of Radioecology. In many cases, however, they cannot give reasonably precise data, or it is simply impossible, due to the extremely low concentration of the radionuclide or its very long half-life, or both.In these situation is better to measure $\mathrm{N}$ instead of A.That is possible by using mass spectrometry techniques where the application of electric and magnetic fields to a charged beam that contains the radionuclide of interest produce a deviation of its trajectory according to its mass and energy.

Accelerator Mass Spectrometry (AMS) is a veteran mass spectrometry technique which consists of the coupling of a mass spectrometer to an accelerator of tandem type. Its sensitivity has made it a very competitive analytical technique.In fact very long lived radionuclides can be determined with sensitivities close or below one part in $10^{15}$. A brief description of AMS is given in the next Section. After that its application to the measurement to key radionuclides in Radioecology are discussed.

\section{Methods}

AMS was proposed for the first time by Alvarez and Cornog 1939 which used a cyclotron to identify ${ }^{3} \mathrm{He}$ in Helium. Under its actual form, however, AMS appears by 1977 (Gove et al. 2010) as a way to solve the limitations of conventional radiometric techniques for ${ }^{14} \mathrm{C}$ dating. After this moment it has rapidly evolved to find application in many disciplines. One of them, the measurement of Environmental Radioactivity. 


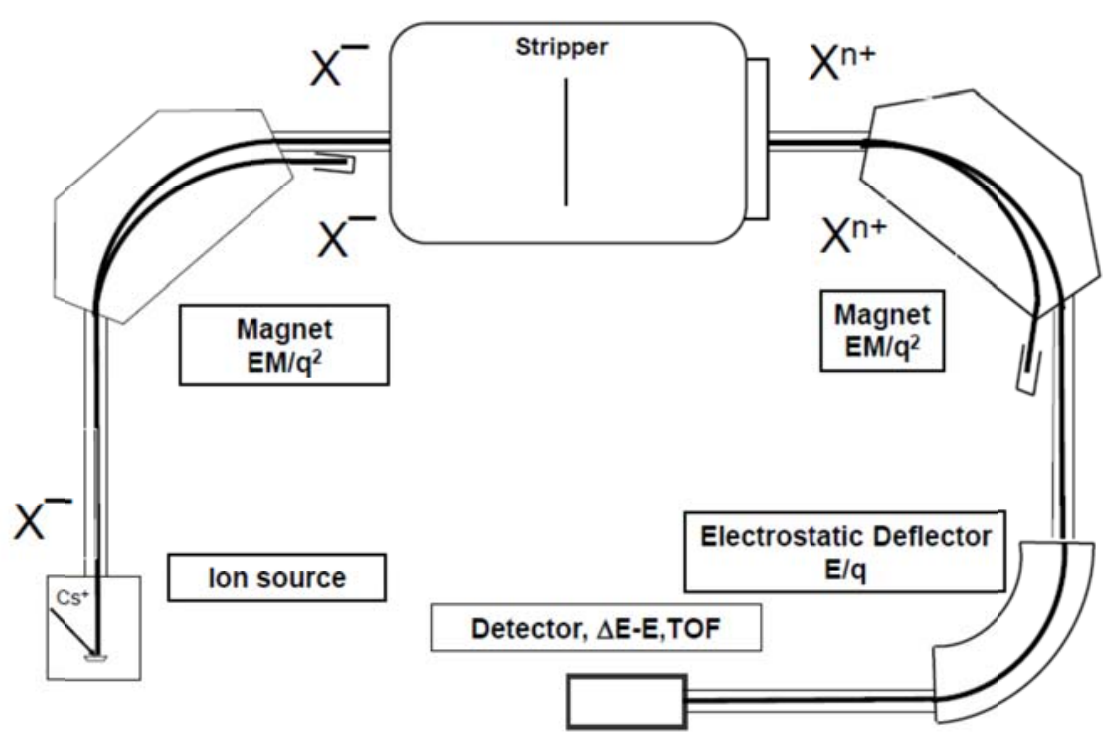

Figure 1.AMS typical system. It is a scheme of the CNA 1 MV Cockcroft-Walton spectrometer.

In Figure 1 we present a simplified scheme of an AMS system which is well representative of many working systems all along the world.The beam, containing the radionuclide of interest is extracted from the sample in the ion source at a charge state $1^{-}$. In the low energy side of the system, the beam is analyzed for mass with a magnet. After that it is injected in the accelerator tank where it is accelerated in two steps. First, before the stripping and then, after the stripping process during which the beam becomes positively charged after its interaction with the stripper. The possitive beam is analyzed once more for mass and energy at the high energy side of the spectrometer with a magnet and a electrostatic deflector. The selected mass is then driven to the radiation detector where the number of radionuclides of interest are counted.

The advantages of AMS regarding conventional mass spectrometry come basically from two special features. First, the dramatic lowering of the molecular background as a consequence of the stripping process, since the majority of molecules are unstable under the resulting strong positive charge state. Second, since the beam is accelerated until energies of the order of MeV/nucleon, it is possible to use nuclear radiation detectors and, consequently, to add to the problem new boundary conditions that permit the discrimination of isobaric species. The use of $\Delta \mathrm{E}$-E telescopes make possible the measurement of stopping powers and the application of the Bethe-Bloch equation to distinguish isobars. Or the use of Time of Flight Spectrometers allows the measurement of different masses, even slightly different masses, at the same energy. As an additional advantage, the use of negative ions at the beginning of the process makes a previous selection of the ions injected in the system. This is very convenient for many radionuclides. In fact, the discovery of the unstability of ${ }^{14} \mathrm{~N}^{-}$, the main interferent of ${ }^{14} \mathrm{C}$, gives place to the development of a new radiocarbon dating technique based on AMS as described above (Gove et al. 2010).

At these conditions the sensitivity one can reach with AMS makes it a really powerful tool to afford many problems in Environmental Sciences and other disciplines. A good review on the sensitivity of AMS for many cases can be found in Tuniz and Norton 2008.

The main drawback of the technique has been the need of large facilities. Nevertheless, since the beginning of this century it has been developed the so called Low Energy AMS with uses low terminal voltage accelerators (below $1 \mathrm{MV}$ ) and small dimensions machines. An example is the National Center for Accelerators (CNA) AMS system based on1MV Cockcroft-Walton tandem accelerator. The dimensions of such spectrometer are relatively small, 3.8x6.3 $\mathrm{m}^{2}$. Even smaller systems can be fairly competitive in AMS. An example is the Spanish MICADAS, 3x2.5 meters in 
size, based on a $200 \mathrm{kV}$ van de Graaff accelerator. This system is devoted in CNA to ${ }^{14} \mathrm{C}$ measurements. Both are described in Chamizo et al $2015 a$.

There is an ample documentation about how AMS can succesfully meet Radioecology problems. In practical terms the main adavantages of AMS is providing extremely good precision in the measurement for very small samples and using low counting times. Indeed, g or mg for solid samples or few $\mathrm{L}$ or fraction of $\mathrm{L}$ for liquid samples are very common in the majority of AMS experiments. Counting times of some 20 min for ${ }^{129} \mathrm{I}$ are enough to obtain precissions of $<10 \%$ forits determination with current methods. Another illustrative example is the case of the measurement of Pu-isotopes in environmental samples where some $15 \mathrm{~min}$ of counting gives results with a precission of $5 \%$ and the additional advantage of measuring ${ }^{239} \mathrm{Pu}$ and ${ }^{240} \mathrm{Pu}$. This is simply impossible to achieve with conventional radiometric methods.

The application of AMS to the measurement of radionuclides in waters, sediments, biota, etc., i.e. to some relevant problems for Radioecology, needs new radiochemical methods for sample preparation. Indeed, the final chemical form of the radionuclide to be measured has to be compatible with the mass spectrometer ion source.

There are many examples in the literature about such developments. One of them is the procedure developed at CNA by Chamizo et al. 2008 for the separation of $\mathrm{Pu}$ from different matrices basedon the use of TEVA resins. The main potential interferents in this case are ${ }^{238} \mathrm{U}$ and Dy isotopes. ${ }^{238} \mathrm{U}$ may reach the detector even in the case the spectrometer is tunned for ${ }^{239} \mathrm{Pu}$, due to, for instance, instrumental unstabilities. ${ }^{160} \mathrm{Dy}^{2+}$ has the same $\mathrm{M} / \mathrm{q}$ ratio that ${ }^{240} \mathrm{Pu}^{3+}$ and, therefore can also be counted by the detector. The method provides good decontamination factors that makes posible the measurement of ${ }^{239} \mathrm{Pu}$ down to fg levels. Pu is injected in the spectrometer as $\mathrm{Pu}$ oxide.

Another interesting example is that presented by Gómez-Guzmánet al. 2010 also at CNA for the separation of ${ }^{129}$ I from lichens based on a microwave digestion which significantly diminishes the processing time regarding the conventional leaching or combustion based methods. As a last step of the method, Iodine is precipitated as AgI.

\section{Results}

The range of applications of AMS and the number of radionuclides that can be measured with such a technique are still expanding. Nowadays, however, the most relevant radionuclides for Radioecology can be tried by AMS. A very brief summary of such applications are given in what follows.

\section{${ }^{14} \mathrm{C}$}

In the case of ${ }^{14} \mathrm{C}$, its main role in AMS is dating. In fact, as it was said before, AMS based on tandem machines was developed to overcomethe limitations of ${ }^{14} \mathrm{C}$ dating by radiometric methods. For that the discovery of the instability of ${ }^{14} \mathrm{~N}^{-}$was a fundamental starting point (Gove et al. 2010). But the advantages of AMS can be used to determine ${ }^{14} \mathrm{C}$ in environmental samples.

A beautiful example is the use of ${ }^{14} \mathrm{C}$ to trace seawater masses movements. In Gislefoss et al. 1994, AMS was used to repeat several GEOSEC Nordic Seas water profiles previously measured by conventional radiometric techniques. AMS allowed to use $0.5 \mathrm{~L}$ water samples instead of 100 to $200 \mathrm{~L}$ needed for traditional techniques. That is very important in order to make the sampling in a cruise expedition and manage the samples after at the laboratory.The authors claim to obtain $6 \%$ ooprecision or better with some 20 min counting time per sample. Interesting information is presented in the paper about the $\mathrm{CO}_{2}$ uptake in the Nordic Seas and its transport into deep waters. Also the age of deep waters is estimated and the authors conclude that the meaurement of ${ }^{14} \mathrm{C}$ by traditional techniques in deep waters "has come to an end".

Radiocarbon is considered to be the most important contributor for the collective total dose received by the population from nuclear fuel processes (UNSCEAR, 2008). For that it is very important to know its behaviour and fate in affected environments. A typical study case is that 
presented byTierney et al. 2016 on the presence of ${ }^{14} \mathrm{C}$ in the Irish Sea and West of Scotland as a result of Sellafield activities. The authors find a general ${ }^{14} \mathrm{C}$ enrichment of mussels and shell material above the background level. A time series study show that the enrichment level in mussels is decreasing as the Sellafield releases have decreased along the time. However, the enrichment is still increasing in sediments. A similar study is presented by the same group but for the Eastern UK coastal environment (Muir et al. 2015). Anomalous ${ }^{14} \mathrm{C}$ enrichment are found in the samples analysed, biota and sediments, and some possible ${ }^{14} \mathrm{C}$ sources are suggested. On the other hand, by dating the sediments with ${ }^{210} \mathrm{~Pb}$, the authors find that the ${ }^{14} \mathrm{C}$ releases are being produced since1960 til the present days.

Inputs of radiocarbon from the Fukushima accident into the sea has been also investigated (Povinec et al. 2016). Impact has been determined but in general terms the contribution of Fukushima ${ }^{14} \mathrm{C}$ was only $9 \%$ above global fallout level. Interesting to say is that the amount of seawater sample to extract $\mathrm{CO}_{2}$ for ${ }^{14} \mathrm{C}$ AMS analysis was typically of $20 \mathrm{~mL}$. The uncertainty in the measurements were $5 \%$ o.

The analysis of ${ }^{14} \mathrm{C}$ in tree rings is a good way to determine the environmetal impact from Nuclear Facilites in their close environment. An example of these type of works appears in Janovics et al. 2016 where a study is carried out on the impact of a low to intemediate level radioactive wastes disposal installation on nearby trees. Radiocarbon is measured in rings from a tree situated close to the facility and from a tree far from the site in order to compare results. As expected, rings of the nearby tree shows a ${ }^{14} \mathrm{C}$ time pattern distribution unambiguously related to the radioactive wastes disposal plant.

A very complete analysis of the impact of a Nuclear Power Plant based on ${ }^{14} \mathrm{C}$ appears in Wang et al. 2014. Seawater, undergroundwaters, river waters and drinking waters, together with atmospheric samples are analysed for ${ }^{14} \mathrm{C}$ by AMS. Samples of some $1 \mathrm{~L}$ were enough to give ${ }^{14} \mathrm{C}$ with less than $1 \%$ uncertainty. The authors find that air samples present impact from the operation of the plant while seawaters give results which are not distinguishable from the background.

In CNA, ${ }^{14} \mathrm{C}$ measurements are mainly addressed to dating works (Santos et al. 2009). Nevertheless, environmental applications are also done. In Beramendi-Orosco et al. 2015, data are presented on the measurement of atmospheric samples at Mexico City. Specifically ${ }^{14} \mathrm{C}$ is determined in tree rings collected at a park within the metropolitan area of the city. The typical ${ }^{14} \mathrm{C}$ bomb pulse with a peak at 1964 is found, but a detailed studied of the results obtained in comparison with similar data taken at the Northern Hemisphere shows a ${ }^{14} \mathrm{C}$ depletion (up to 246\% lower than the expected backgorund)atributted to the vast fossil fuel consumed in the area. Few mg samples and some half an hour of measurement is enough to get a very precise measurement of ${ }^{14} \mathrm{C}$ in each ring.

${ }^{129} I$

The development of AMS has been crucial for ${ }^{129}$ I. It has a very long half-life and is very diluted in ${ }^{127} \mathrm{I}$. Therefore, its measurement by conventional radiometric methods is only posible under very special circumstances. Pioneering works on AMS of ${ }^{129}$ I dates back to Elmore et al 1980 and later to Kilius et al. 1990. After this work the information on the presence of ${ }^{129} \mathrm{I}$ in the environment has increased outstandingly. The review by Raisbeck and Yiou, 1999 is a good reference on how AMS benefited the ${ }^{129} \mathrm{I}$ "environmental science”, specially in oceans, since ${ }^{129} \mathrm{I}$ is a well recognised tracer of water movements, as the authors themselves proposed. By that time, it was posible to measure ${ }^{129}$ I in only $1 \mathrm{~L}$ water sample volume with an uncertainty better than $10 \%$. The authors analyze the vertical and horizontal distribution pattern of ${ }^{129} \mathrm{I} /{ }^{127} \mathrm{I}$ in North Atlantic Ocean and combine these data with those of ${ }^{137} \mathrm{Cs}$ and ${ }^{99} \mathrm{Tc}$. Thus obtaining an ample oceanographic information on the area.

The sensitivity of AMS has made possible the measurement of ${ }^{129} \mathrm{I}$ in surface fresh waters. Aldahan et al. 2006 studied its presence in rivers of the Baltic area. 1L samples were enough to obtain precise ${ }^{129} \mathrm{I}$ concentrations. The origin of ${ }^{129} \mathrm{I}$ in the rivers was attributed to atmospheric 
inputs from the Baltic Sea which in turn is affected by Sellafield and La Hague nuclear fuel reprocessing plant. Being others contributions as global fallout or Chernobyl inputs negligible.

${ }^{129} \mathrm{I}$ in the amosphere has been also an important topic. A good review of ${ }^{129} \mathrm{I}$ in air can be found in Jabal et al. 2013. And it is a target of the CNA studies. AMS allowed a high time resolution analysis on its presence in Sevilla, Spain, an area not affected by nuclear facilities. Results presented in Santos et al. 2006 gave information on ${ }^{129}$ Iconcentration and the ratio ${ }^{129} \mathrm{I} /{ }^{127} \mathrm{I}$ of aerosol and rainwater samples. These measurements allowed the authors to conclude the influence of the atmospheric emissions of Sellafield and La Hague over the area and suggest the possibility that such discharges were done in an aerosol form or in a chemical form that associates rapidly to aerosol which facilitates the arriving to Sevilla.

More recently, measurements have been done of ${ }^{129} \mathrm{I}$ in aerosol samples and $0.5 \mathrm{~L}$ rainwater samples during March and April 2011 when the radioactive Fukushima plume arrived Spain (Gómez-Guzmán et al. 2016). ${ }^{131}$ I was also measured. The analysis showed the ${ }^{129}$ I impact in Sevilla and according to the data it is suggested to use it as a marker of ${ }^{131}$ I radiological impact. The same conclusion is derived by Muramatsu et al. 2015 that analysed both I isotopes in soils close to Fukushima.

Once more the sensitivity of AMS allowed to determine it in a sediment core taken at Huelva, SW Spain, a non affected place by direct emissions, during 1999 (Santos et al. 2007). Only $2 \mathrm{~g}$ of sediments were enough to clearly identify three sections in the profile. The older layers corresponding to the pre-nuclear era, a prominent peak corresponding to the $1964 \mathrm{bomb}$ pulse and the more young layers which reflect the influence of Sellafield and La Hague in the area.

As said before, there is a wide scientific literature on the presence of ${ }^{129} \mathrm{I}$ in the marine environment. It has also been studied by the CNA group. Results in seaweed and water samples taken in the Baltic area were presented in Gómez-Guzmán et al. 2013 and Gómez-Guzmán et al. 2014. It was possible to show that the main contributionsto this area comes from the releases of Sellafield and La Hague and that the contribution of ${ }^{129}$ I from Chernobyl was not significant. An interesting comparison is done on the concentration of ${ }^{129} \mathrm{I}$ in the South and North Atlantic áreas (López-Gutiérrez et al. 2016).

The sensitivity of AMS has permitted to makespeciation studies of ${ }^{129} \mathrm{I}$ in waters from the Baltic Sea and in the surroundings of the Savannah River site contaminated by the Savannah atmospheric emissions. Speciation works are key studies in radioecology as it is known. For long half-life radionuclides it is only posible by very sensitive techniques, AMS in our case. Iodide and iodate forms for ${ }^{129} \mathrm{I}$ are identified in waters from the Baltic Sea in Hansen et al. 2011. The authors compare it with the same analysis for ${ }^{127} \mathrm{I}$ and do not find differences in this environmental context. In the case of waters from the Savannah (Schwehr et al. 2014) the authors find a clear dependency on $\mathrm{pH}$ of the ${ }^{129} \mathrm{I} /{ }^{127} \mathrm{I}$ isotopic ratio for each chemical species.

\section{${ }^{36} \mathrm{Cl}$}

The determination of ${ }^{36} \mathrm{Cl}$ by AMS is a classic topic in this field. The first work was published in 1979 (Elmore et al. 1979) on the analysis of ${ }^{36} \mathrm{Cl}$ in natural water samples requiring only 1 to $5 \mathrm{~L}$. In this pioneer paper the principles of ${ }^{36} \mathrm{Cl}$ detection by AMS were presented for the first time. Rejection of ${ }^{36} \mathrm{~S}$, its main interferent, was done with a gas ionisation based $\Delta \mathrm{E}-\mathrm{E}$ telescope. Uncertainties in measurements were $<10 \%$ in less than $1 \mathrm{~h}$ counting time.Since that paper many works have been producedon the determination of ${ }^{36} \mathrm{Cl}$ in different samples. The main application being dating groundwaters or tracing its dynamics. An interesting work on that issue was published by Balderer and Synal 1997. In this paper the authors carry out a detailed study of the presence and sources of ${ }^{36} \mathrm{Cl}$ in groundwaters and develop a model for the application of ${ }^{36} \mathrm{Cl}$ to understand the groundwater cycle. The extremely precise ${ }^{36} \mathrm{Cl}$ AMS measurements make possible to inform on residence times, age, evaporation porcesses, water-rock interactions etc. 
${ }^{36}$ Clhas been used also as a tracer of the environmental contamination provoked by contaminated Chernobyl material buried in trenches in the exclusion zone. Indeed, Roux et al. 2014studied the presence of ${ }^{36} \mathrm{Cl}$ in underground waters in the surroundings of one of these trenches. Results shown that ${ }^{36} \mathrm{Cl}$ is a suitable tracer in this context and ${ }^{36} \mathrm{Cl} / \mathrm{Cl}$ ratios some 3 to 4 orders of magnitudes higher than foreseen at natural conditions were found. Once again the amount of sample needed for analysis was small, 1 to $6 \mathrm{~L}$ each. The choice of ${ }^{36} \mathrm{Cl}$ as a tracer was based in the assumption of its conservative behaviour in waters. A recent work describes, however, a ${ }^{36} \mathrm{Cl}$ non-conservative behaviour in the Great Lakes (Poghosyan and Sturchio 2015).

The presence of ${ }^{36} \mathrm{Cl}$ in the atmosphere has received attention from seveeral groups. ${ }^{36} \mathrm{Cl}$ in rainwater samples taken at Sevilla, Spain, during 1999 and 2000 was studied and results presented in Santos et al. 2004. Uncertainties < $10 \%$ in ${ }^{36} \mathrm{Cl}$ atom concentrations and ${ }^{36} \mathrm{Cl} / \mathrm{Cl}$ isotopic ratios are obtained by analysisng no more than $5 \mathrm{~L}$ of water. Results revealed a seasonal time pattern variation with peaks during late spring-early summer. The influence of "dead" Cl carried by (SW) winds from the Atlantic ocean is also shown. Furthermore, the authors found that the ${ }^{36} \mathrm{Cl}$ total atmospheric deposition in the area was higher than expected from the known cosmogenic models for ${ }^{36} \mathrm{Cl}$ production. This effect was previously discovered by Blinov et al. 2004. The authors measured the atmospheric ${ }^{36} \mathrm{Cl}$ deposition worldwide and detected an systematic excess compared to the calculations from the known cosmogenic models. They attributed such effect to the retention of ${ }^{36} \mathrm{Cl}$ bomb produced in the biosphere ad its afterward reintroduction in the atmosphere.The seasonal time variation has been confirmed by Tosaki et al 2014 with atmospheric samples taken at central Japan. In this publication measurements of ${ }^{36} \mathrm{Cl}$ monthly flux over Japan have been carried out from 2004 to 2009. The influence of the sea spray is also demonstrated on the $\mathrm{Cl}$ content in the atmosphere.

\section{Pu-isotopes}

The importance of $\mathrm{Pu}$ isotopes in Radioecology is well known. The determination of $\mathrm{Pu}$ isotope ratios, mainly ${ }^{240} \mathrm{Pu} /{ }^{239} \mathrm{Pu}$ is, on the other hand of paramount relevance to know the source term of $\mathrm{Pu}$ in a given environment. Efforts have been done to measure such ratios by $\alpha$ spectrometry but only in very special circumstances,and with the help of $\alpha$-spectra deconvultion codes, it has been posible. In addition, $\alpha$ spectrometry is time consuming with days of counting often necessary to determine $\mathrm{Pu}$ in environmental samples. On the contrary, AMS is less time consuming and uses smaller amount of sample to get better precision. And, above all, it gives the ${ }^{240} \mathrm{Pu} /{ }^{239} \mathrm{Pu}$ isotope ratio. And without the need of large facilities in spite of the high mass of the Pu isotopic family. Fifield et al. 2004 demonstrated the possibility of measuring Pu isotopes with $300 \mathrm{kV}$ terminal voltage accelerators.

In the CNA group an extensive development of methodology has been carried out for the determination of $\mathrm{Pu}$ isotopes in a variety of environmental samples.

This way $\mathrm{Pu}$ isotopes and ratios have been determined in the Palomares environment, SE Spain, affected by an accident occurred in 1966 when the fuel from two termonuclear bombs spread in it. Previous studies have been carried out in the site by measuring ${ }^{239+240} \mathrm{Pu}$ activity or ${ }^{238} \mathrm{Pu} /{ }^{239+240} \mathrm{Pu}$ activity ratios but this has not shown to be enough to characterize and identify the dispersion of $\mathrm{Pu}$ originated in the accident. Chamizo et al. 2006 measured ${ }^{240} \mathrm{Pu} /{ }^{239} \mathrm{Pu}$ isotope ratio in soil samples from Palomares by Low Energy AMS (LEAMS). Small, 1-2 g of soil samples were measured with low and high level of contamination and the results compared to those found in soils from Sevilla affected only by fallout. Typical values for the atom ratio of around $17 \%$ was found for the Sevilla samples while a typical atom ratio of $(6.57 \pm 0.06) \%$ was measured for highly contaminated samples from Palomares, showing this way the utility of measuring the ratio to unambiguously assign the origin of $\mathrm{Pu}$ in the studied area. Later, Chamizo et al. 2010a were able to determine ${ }^{240} \mathrm{Pu} /{ }^{239} \mathrm{Pu}$ also by LEAMS in a sediment core taken offshore Palomares. Results shown that the sediment was affected by the releases from the accident since the ratio was found to be $11 \%$ 
in the average along the profile. Ratios close to $6 \%$ were found in the first $\mathrm{cm}$ of the profile where as calculated the majority of Pu coming from the accident accumulated. Results confirmed a land to sea transport of contamination in this case.

The sensitivity of AMS made possible to measure the ${ }^{240} \mathrm{Pu} /{ }^{239}$ Puisotope ratio in soils samples from Southern Hemisphere, specifically from Chile (Chamizo et al. 2011). It was possible to detect the influence of French tests in some of the samples by measuring the isotope ratio which values close to $4 \%$. In other cases, ratios of $18 \%$, the fallout signal in the area, were obtained.

Also with the AMS sytem of the CNA, Chamizo et al. $2010 b$ measured the temporal evolution of Pu-isotopes in surface air samples collected in Sevilla. On the average $6 \mathrm{~g}$ of aerosol, i. e. some $30.000 \mathrm{~m}^{3}$ of filtered air, were enough to obtain $\mathrm{Pu}$ concentrations with uncertainties of some few \% using counting times of $30 \mathrm{~min}$. A seasonal pattern was found with maximun activites corresponding to the dry summer and minimum corresponding to the following autumn rainy period, this in agreement with the hypothesis of a soil resuspension effect as the origin of $\mathrm{Pu}$ in this area. Correlation was found of $\mathrm{Pu}$ concentrations with the aerosol mass and the content of $\mathrm{Ti}$ and Al. This indicated a possible modulation of the Pu-isotpes activities in the air of Seville by Saharian dust intrusion. ${ }^{240} \mathrm{Pu} /{ }^{239} \mathrm{Pu}$ ratio was typically of $14 \%$, close to the expected fallout ratio in the region of around $18 \%$.

AMS has been shown to be a very important tool to meet, in a precise and realistic way, the measurement of ${ }^{239} \mathrm{Pu}$ in human urine samplesfor routine monitoring of exposed workers. Traditionally this work is done by analysing large volumes of urine samples. Moreover the whole measurement by $\alpha$-spectrometry takes one week including the radiochemical separation of $\mathrm{Pu}$. Hernández- Mendoza et al. 2010 developed a method using the CNA AMS system to analyse Pu in urine samples using only 1-2 L. The whole measurement takes $10 \mathrm{~h}$ including chemical processing.

With regard also to the operation of nuclear power plants, it is important to have methodology for the classification of wastes in low, medium or high level. This is conventially done by studying the activites of long-lived radionulides in them by radiometric methods, which are time consuming, laborious and necessarily have to treat high volumeof samples, which means dangerous methods. As López-Gutiérrez et al. 2013demonstrated, AMS provides a fast and less laborious method using significantly less amount of sample. They measured ${ }^{240} \mathrm{Pu} /{ }^{239} \mathrm{Pu}$ and ${ }^{129} \mathrm{I}$ in wastes from Spanish Nuclear Power Plants including materials from the decommissioning of one of them. They showed that meauring activity ratios can be give additional information about the history of the residue.

$\mathrm{Pu}$ speciation studies are possible with AMS. Skipperud et al. 2009 presented Pu speciation studies in waters and sediments from the $\mathrm{Ob}$ and Yenisey rivers and estuaries in Russia. Knowledge of chemical association of the Pu isotopes gives unvaluable information on their transfer, fate and environmental impact in the Baltic Sea in that case. The authors found that more than $80 \%$ of the $\mathrm{Pu}$ in the Yenisey river is very weakly bound, i.e. associated to organic compunds. This pattern changes when going from the riverine to estuarine area, where $\mathrm{Pu}$ is more strongly and irreversibly bound.

${ }^{236} U$

${ }^{236} \mathrm{U}$ is a very new member of the AMS family. In fact, only few years ago ${ }^{236} \mathrm{U}$ has been recognised as a good tracer for marine dynamics or others environmental processes. Nevertheless, the measurement of ${ }^{236} \mathrm{U}$ is impossible by radiometric methods and it is a very challenging isotope for AMS. In spite of that the amount of literature on AMS of ${ }^{236}$ Uhas increased during the last years.

Sakaguchi et al. 2010 reported a study of the fallout from the Hiroshima bomb by using ${ }^{236} \mathrm{U}$ together with other nuclides. Its presence at the site was expected from the fast neutron activation reaction ${ }^{235} U(n, \gamma)$ occurred during the detonation of the A-bomb.Data obtained shown that it was not posible to distinguish between global ${ }^{236} \mathrm{U}$ falloutand the current level found for it at the zone. 
The authors concluded that less than $1 \%$ of the ${ }^{236} \mathrm{U}$ produced in the detonation deposited in the area.

The global ${ }^{236} \mathrm{U}$ fallout signal has been measured by Srncik et al. 2011 in soils collected from a remote clean air area in the La Palma Isle in Canary Islands, Spain. Some few grams per sample were analyzed and counting times of around 30-60 min were typically used. ${ }^{236} U$ concentrates in the first $\mathrm{cm}$ of the soil profile. The atom ratio ${ }^{236} \mathrm{U} /{ }^{238} \mathrm{U}$ ranges from $10^{-7}$ to $10^{-9}$. The global fallout U-isotope ratio is sparce according to the authors in soils.

Eigl et al. 2013 measured ${ }^{236} \mathrm{U}$ in seawater and river waters (only $2 \mathrm{~L}$ ). ${ }^{236} \mathrm{U} /{ }^{238}$ Uratios were found of $10^{-9}$ in marine and $10^{-8}$ in river waters. The authors atributted to global fallout such results. More recently, Srncik et al. 2014 were able to determine ${ }^{236} \mathrm{U}$ in soils of the Southern hemisphere from unaffected areas. The atuhors provide results on the ${ }^{236} \mathrm{U}$ inventory in the Southern Hemisphere, which is found to be $8.4 \times 10^{11}$, one order of magnitude lower than in the Northern Hemisphere. The ratio ${ }^{236} \mathrm{U} /{ }^{239} \mathrm{Pu}$ was 0.08 clearly lower than the ratio at the Northern Hemisphere, typically 0.2.Related to this work, Froehlich et al. 2016 studied the uptake of ${ }^{236} \mathrm{U}$ by plants in the Southern Hemisphere by AMS. Compared to ${ }^{239} \mathrm{Pu},{ }^{236} \mathrm{U}$ seems to be uptaken preferentially by vegetation.

In Chamizo et al. 2016a, data are presented on ${ }^{236} \mathrm{U}$ in a peatbog core collected at Madagascar. Ratios ranging from 0.02 to 0.29 are found for ${ }^{236} \mathrm{U} /{ }^{239} \mathrm{Pu}$ which complete the datafile for these nuclides in the Southern Hemisphere.

Documentation is already published on the ${ }^{236} \mathrm{U}$ dynamics and presence in oceans. Eigl et al. 2016, presented results of ${ }^{236} \mathrm{U}$ depth water profiles from the Northeast Pacific Oceans. They obtain very precise data with only $1 \mathrm{~L}$ sample volumen. ${ }^{236} \mathrm{U}$ concentrations are higher in surface samples than in deep waters. This reflecting, according to the authors, the low vertical transport of waters in this region, and consequently the large age of deep waters. ${ }^{236} \mathrm{U} /{ }^{238} \mathrm{U}$ ratio is also higher at the surface, ranging from $10^{-9}$ at the surface to $10^{-10}$ at $1500 \mathrm{~m}$ and deeper. Villa et al. 2016, on the other hand, present in these Proceedings results on ${ }^{236} \mathrm{U}$ in the Equatorial area of the Pacific Ocean.Also based in measurements carried out in the AMS CNA system, López-Lora et al. 2016, have measured ${ }^{236} \mathrm{U}$ in South Atlantic water samples. ${ }^{236} \mathrm{U} /{ }^{238} \mathrm{U}$ ratios of some $10^{-10}$ are obtained lower than those presented by Eigl et al. 2016 of $10^{-9}$ for North Atlantic samples which points to an influence in this region of a local contamination coming from the nuclear reprocessing plants. The same CNA group together with that from IAEA-Environment Laboratory at Monaco (Chamizo et al. 2016b) have determined ${ }^{236} \mathrm{U}$ in the Northwestern Mediterranean area. In this case the ${ }^{236} \mathrm{U} /{ }^{238} \mathrm{U}$ atom ratio reached a value of $10^{-9}$ indicating that anthropogenic ${ }^{236} \mathrm{U}$ dominates the whole water column. Some $5 \mathrm{l}$ samples were used and around 25 min was the counting time per sample. The ${ }^{236} U$ inventory in the water column is 2 times higher than expected in this area. The authors consider that several additional sources to global fallout has to be taken into account to explain the ratio, such as French Nuclear Power Plants, remaining traces from Chernobyl and even Sahara dusts. Interesting to say is that the CNA measurements have been done by a Low Energy AMS (LEAMS). A full account of the method is given in Chamizo et al. 2015b. In fact, the possibility of measuring ${ }^{236} \mathrm{U}$ by LEAMS was propossed by Vockenhuber et al. 2011. It made available the technique to many groups.

\section{Others}

Non regular applications of AMS to interesting isotopes for radioecology can be found in literature.

${ }^{99}$ Tc has been investigated by AMS. Its determination in the environment by AMS was reported by Fifield et al. 2000. A technical effort was done in the paper to separate ${ }^{99} \mathrm{Tc}$ from ${ }^{99} \mathrm{Ru}$ and AMS was shown to be able to determine it at fg levels. Some first measurements were done in seaweed intercalibration samples.The method was refined by Wacker et al. 2004. Close in the time Bergquist et al. 2000 published another AMS ${ }^{99}$ Tc method. Good separation from ${ }^{99} \mathrm{Ru}$ and molecular backgrounds was obtained by the authors with $\mathrm{MeV}$ beam energies. The method was 
applied to fresh and sea waters, some $200 \mathrm{~mL}$ in volume, and arid soils, around 60 to $100 \mathrm{~g}$. After these works, it seems, however, that no suystematic applications of AMS to Tc can be found in regular literature, although new approaches to the problem were presented by Ming et al. 2007.

${ }^{90} \mathrm{Sr}$ or ${ }^{135} \mathrm{Cs}$ has been meaured also by AMS in Tumey et al. 2008 and Mc Donald et al. 2015 respectively. In the first case the main challenge lies on the discrimination against ${ }^{90} \mathrm{Zr}$. In their work the authors wait to achieve a sensitivity of $10^{690} \mathrm{Sr}$ atoms per sample after some expected developments. The case of ${ }^{135} \mathrm{Cs}$ is very special since Cs does not easily forms negative ions. In fact, it has to be injected into the accelerator as $\mathrm{CsF}_{2}{ }^{-}$and a Isobar Separator for Anions has to be used to reject the Ba contamination of the sample. The paper provides promising first results.

Very recently measurementsof Am and Cm isotopes by LEAMS has been carried out (Christl et al. 2015). Sensitivities of $\sim$ fg or even $\sim 10^{-1} \mathrm{fg}$ for Am and Cm isotopes respectively are achieved by using a $500 \mathrm{kV}$ terminal voltage tandem accelerator. The radionuclides are accelerated in oxide form.

${ }^{237} \mathrm{~Np}$ is receiving an increasing attention within the AMS community. Radiochemical methodology can be found in Hain et al. 2015 and Levy et al. 2016, both for small (fractions or few $\mathrm{L}$ as much) seawater. The work by Wang et al. 2010 presents ${ }^{237} \mathrm{~Np}$ standards for AMS.

AMS studies are being done for $\mathrm{Pb}$ isotopes, including ${ }^{210} \mathrm{~Pb}$ (Sookdeo et al. 2015). The accelerated species is $\mathrm{PbF}_{3}^{-}$.

\section{Conclusions}

Since 1977 tandem accelerator based AMS using negative ions has evolved enormously. Important improvements in precission and sensitivity have been achieved since which has converted AMS in an essential tool for many scientific disciplines. That is the case of Radioecology, where the possibility of analysing small samples, during short counting times together with the increasing number of detectable radionuclidesmake it a very useful analytical technique. As a consequence, the applications of AMS to Radioecology are exponentially increasing. Furthermore, the appearing of small and compact machines as aproduct of the development of the so-called Low Energy AMS (LEAMS) has made AMS available to many laboratories.Summing up the sensitivity one can reach with AMS makes it a really powerful tool to afford many problems in Environmental Sciences and Radioecology as it can be seen in Fig. 2

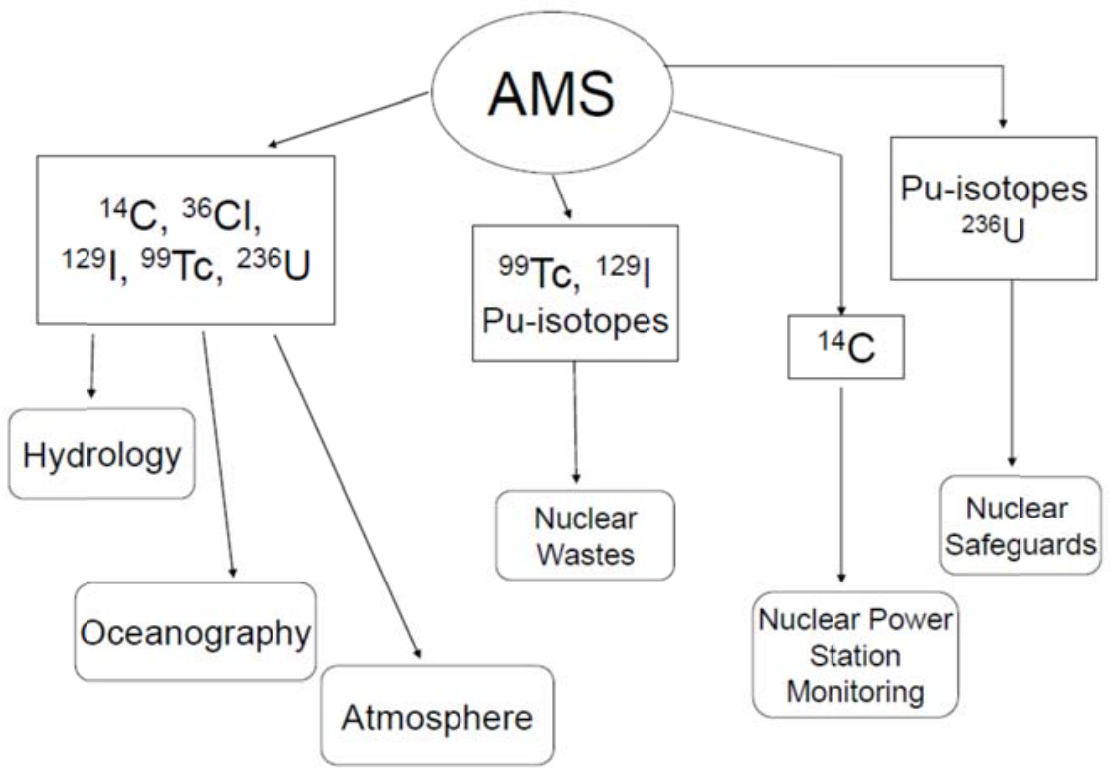

Figure 2.AMS impact on Environmental Radioactivity and Radioecology studies through the measurement of relevant radionuclides. 


\section{References}

Aldahan A., Kekli A., Possnert G., 2006, Distribution and sources of ${ }^{129}$ I in rivers of the Baltic region, J. Environ. Radioact. 88, 49-73.

Alvarez L. W., Cornog R., 1939, ${ }^{3}$ He in helium, Phys. Rev. 56, 379.

Balderer W., Synal H. A., 1977, Use of chlorine-36 as tracer for the evolution of waters in geotermal and tectonically active areas in Western Turkey, Nuc. Instrum. and Meth. in Phys. Res. B123, 387-393.

Beramendi-Orosco L., Gonzalez-Hernandez G., Martinez-Jurado A., Martinez-Reyes A., Garcia-Samano A, Villanueva-Diaz J., Santos-Arevalo F. J., Gomez-Martinez I., Amador-Muñoz O., 2015, Temporal and spatial variations of atmospheric radiocarbon in the Mexico City metropolitan area, Radiocarbon, 57, 363375.

Bergquist B. A., Marchetti A. A., Martinelli R. E., McAninch J. E., Nimz G. J., Proctor L. D., Southon J. R., Vogel J. S., 2000, Technetium measurements by accelerator mass spectrometry at LLNL,Nuc. Instrum. and Meth. in Phys. Res. B172, 328-332.

Blinov A., Massonet S., Sachsenhauser H., Stan-Sion C., Lazarev V., Beer J., Synal H. A., Kaba M, Masarik J., Nolte E., 2000, An excess of ${ }^{36} \mathrm{Cl}$ in modern atmospheric precipitation, Nuc. Instrum. and Meth. in Phys. Res. B172, 537-544.

Chamizo E., García-León M., Synal H.A., Suter M., Wacker L., 2006, Determination of the ${ }^{240} \mathrm{Pu} /{ }^{239} \mathrm{Pu}$ atomic ratio in soils from Palomares (Spain) by low-energy accelerator mass spectrometry, Nuc. Instrum. and Meth. in Phys. Res. B249, 768-771.

Chamizo E., Jiménez-Ramos M. C., Wacker L., Vioque I., Calleja A., García-León M., García-Tenorio R., 2008, Isolation of $\mathrm{Pu}$-isotopes from environmental samples usingion chromatography for accelerator mass spectrometry andalpha spectrometry, Anal. Chim. Acta, 606, 239-245.

Chamizo E., Jiménez-Ramos M. C., Enamorado S. M., García-León M., García-Tenorio R., Mas J. L., Masqué P, Merino J., Sanchez-Cabeza J. A., 2010a, Characterisation of the plutonium isotopic composition of a sediment core from Palomares, Spain, by low-energy AMS and alpha-spectrometry, Nuc. Instrum. and Meth. in Phys. Res. B268, 1273-1276.

Chamizo E., García-León M., Enamorado S. M., Jiménez-Ramos M. C., Wacker L., 2010b, Measurement of plutonium isotopes, ${ }^{239} \mathrm{Pu}$ and ${ }^{240} \mathrm{Pu}$, in air-filter samples from Seville (2001-2002), Atmospheric Environment 44, 1851-1858.

Chamizo E., García-León M., Peruchena J. I., Cereceda F., Vidal V., Pinilla E., Miró C., 2011, Presence of plutonium isotopes, ${ }^{239} \mathrm{Pu}$ and ${ }^{240} \mathrm{Pu}$, in soils from Chile, Nuc. Instrum. and Meth. in Phys. Res. B24, 31633166.

Chamizo E., Santos F. J., López-Gutiérrez J. M., Padilla S., García-León M., Heinemeier J., Schnabel C., Scognamiglio G., 2015a, Status report of the 1 MV AMS facility at the Centro Nacional de Aceleradores, Nuc. Instrum. and Meth. in Phys. Res. B361, 1-9.

Chamizo E., Christl M., Fifield L. K., 2015b, Measurement of ${ }^{236} \mathrm{U}$ on the 1 MV AMS system at the Centro Nacional de Aceleradores (CNA), Nuc. Instrum. and Meth. in Phys. Res. B358, 45-51.

Chamizo E., López-Gutiérrez J. M., Holm E., García-Tenorio R., 2016a, ${ }^{129} \mathrm{I},{ }^{236} \mathrm{U},{ }^{239} \mathrm{Pu}$ and ${ }^{240} \mathrm{Pu}$ profiles in a peatbog from the Southern Hemisphere. These Proceedings.

Chamizo E., López-Lora M., Bressac M., Levy I., Pham M. K., 2016b, Excess of ${ }^{236} U$ in the northwest Mediterranean Sea, Sci. Total Environ. 565, 767-776.

Christl M., Dai X., Lachner J., Kramer-Tremblay S., Synal H. A., 2014, Low energy AMS of americium and curium, Nuc. Instrum. and Meth. in Phys. Res. B331, 225-232.

Eigl R., Srncik M., Steier P., Wallner G., 2013, ${ }^{236} \mathrm{U} /{ }^{238} \mathrm{U}$ and ${ }^{240} \mathrm{Pu} /{ }^{239} \mathrm{Pu}$ isotopic ratios in small (2 L) sea and river water samples, J. Environ. Radioact. 116, 54-58.

Eigl R., Steier P., Winkler S. R., Sakata K., Sakaguchi A., 2016, First study on ${ }^{236}$ U in the Northeast Pacific Ocean using a new target preparation procedure for AMS measurements, J. Environ. Radioact. 162/163, 244250.

Elmore D., Fulton B. R., Clover M. R., Marsden J. R., Gove H. E., Naylor H., Purser K. H., Kilius L. R., Beukens R. P., Litherland A. E., 1979, Analysis of ${ }^{36} \mathrm{Cl}$ in environmental water samples using electrostatic accelerators, Nature 277, 22-25.

Elmore D., Gove H.E., Ferraro R., Kilius L.R., Lee W., Chang K.H., Beukens R.P., Litherland A.E., Russo C.J., Murell M.T., Finkel R.C., 1980. Determination of ${ }^{129} \mathrm{I}$ using tandem accelerator mass spectrometry. Nature 286, 138-140. 
Fifield L. K., Carling R. S., Cresswell R. G., Hausladen P. A., di Tada M. L., Day J. P., 2000, Accelerator mass spectrometry of ${ }^{99}$ Tc, Nuc. Instrum. and Meth. in Phys. Res. B168, 427-436.

Fifield L. K., Synal H. A., Suter M., 2004, Accelerator mass spectrometry of plutonium at $300 \mathrm{kV}$, Nuc. Instrum. and Meth. in Phys. Res. B223/224, 802-806.

Froehlich M. B., Dietze M. M. A., Tims S. G., Fifield L. K., 2016, A comparison of fallout ${ }^{236} \mathrm{U}$ and ${ }^{239} \mathrm{Pu}$ uptake by Australian Vegetation, J. Environ. Radioact. 151, 558-562.

Gislefoss J. S., Nydal R., Donahue D. J., Jull A. J. T., Toolin L. T., 1994, Tracer studies of ${ }^{14} \mathrm{C}$ in the Nordic Seas by AMS measurements, Nuc. Instrum. and Meth. in Phys. Res. B92, 431-435.

Gómez-Guzmán J. M., López-Gutiérrez J. M., Pinto A. R., Holm E., García-León M., 2010, Analysis of ${ }^{129}$ I in lichens by accelerator mass spectrometry through a microwave-based sample preparation method, Nuc. Instrum. and Meth. in Phys. Res. B268, 1171-1174.

Gómez-Guzmán J. M., Villa M., Le Moigne F., López-Gutiérrez J. M., García-León M., 2013, AMS measurements of ${ }^{129 \mathrm{I}}$ in seawater around Iceland and the Irminger Sea, Nuc. Instrum. and Meth. in Phys. Res. B294, 547-551.

Gómez-Guzmán J. M., Holm E., Niagolova N., López-Gutiérrez J. M., Pinto-Gómez A. R., Abril J. M., García-León M., 2014, Influence of releases of ${ }^{129} \mathrm{I}$ and ${ }^{137} \mathrm{Cs}$ from European reprocessing facilities in Fucus vesiculosus and seawater from the Kattegat and Skagerrak areas, Chemosphere 108, 76-84.

Gómez-Guzmán J. M., López-Gutiérrez J. M., García-Tenorio R., Agulló L., Peruchena J. I., Manjón G., García-León M., 2016, Estimating the impact from Fukushima in Southern Spain by ${ }^{131}$ I and Accelerator Mass Spectrometry detection of ${ }^{129}$ I, J. Environ. Radioact. article in press, 1-9.

Gove H. E., Purser K. H., Litherland A. E., 2010, Accelerator Mass Spectrometry (AMS) 1977-1987, Nuc. Instrum. and Meth. in Phys. Res. B268, xvii-xxii.

Hain K., Faestermann T., Famulok N., Fimiani L., Gómez-Guzmán J. M., Korschinek G., Kortmann F., Lierse v. Gostomski Ch., Ludwig P., Shinonaga T., 2015, Analytical method for the determination of Np and $\mathrm{Pu}$ in sea water by AMS with respect to the Fukushima accident, Nuc. Instrum. and Meth. in Phys. Res. B361, 505-509.

Hansen V., Yi P., Hou X., Aldahan A., Roos P., Possnert G., 2011, Iodide and iodate $\left({ }^{129}\right.$ I and $\left.{ }^{127} I\right)$ in surface water of the Baltic Sea, Kattegat and Skagerrak, Sci. Total Environ. 412-413, 296-303.

Hernández-Mendoza H., Chamizo E., Yllera A., García-León M., Delgado A., 2010, Measurement of ${ }^{239} \mathrm{Pu}$ in urine samples at ultra-trace levels using a 1 MV compactAMS system, Nuc. Instrum. and Meth. in Phys. Res. B268, 1331-1333.

Jabbar T., Wallner G., Steier P., 2013, A review on ${ }^{129}$ I analysis in air, J. Environ. Radioact. 126, 45-54.

Janovics R., Kelemen D. I., Kern Z., Kapitany S., Veres M., Jull A.J.T., Molnar M., 2016, Radiocarbon signal of a low and intermediate level radioactive waste disposal facility in nearby trees, J. Environ. Radioact. 153, 10-14.

Kilius LR, Baba N, Garwan MA et al., 1990, AMS of heavy ions with small accelerators. Nucl Instrum Methods B52, 357-365.

Levy I., Chamizo E., López-Lora M., Bressac M., 2016, Analysis of Pu isotopes and ${ }^{237} \mathrm{~Np}$ in seawater by AMS. These Proceedings.

López-Gutiérrez J. M., Gómez-Guzmán J. M., Chamizo E., Peruchena J. I., García-León M., 2013, Longlived radionuclides in residues from operation and decommissioning of nuclear power plants, Nuc. Instrum. and Meth. in Phys. Res. B294, 647-651.

López-Gutiérrez J. M., Ceballos-Romero E., Stinchcombe M., Vivó-Vilches C., Villa M., 2016, ${ }^{129}$ I Concentrations in the Sputhern Hemisphere: North Atlantic versus Southern Ocean, These Proceedings.

López-Lora M., Chamizo E., Levy I., Rozmaric M., Louw D. C., Blinova O., 2016, First results of 236 in the South-Atlantic Ocean. These Proceedings.

MacDonald C. M., Charles C. R. J., Zhao X. L., Kieser W. E., Cornett R. J., Litherland A. E., 2015, Determination of ${ }^{135} \mathrm{Cs}$ by accelerator mass spectrometry, Nuc. Instrum. and Meth. in Phys. Res. B361, 554558.

Ming H., Shan J., Bo P., Xiangdong R., Kejun D., Yongjing G., Shihong L., Shaoyong W., Jiuzi Q., Xinyi Y., Yanqiu D., 2007, ${ }^{99}$ Tc measurements with accelerator mass spectrometry at CIAE, Nuc. Instrum. and Meth. in Phys. Res. B259, 708-713.

Muir G. K. P., Cook G. T., MacKenzie A. B., MacKinnon G., Gulliver P., 2015, Anomalous ${ }^{14}$ C enrichments in the Eastern UK coastal environment, Radiocarbon 57, 337-345. 
Muramatsu Y., Matsuzaki H., Toyama C., Ohno T., 2015, Analysis of ${ }^{129} \mathrm{I}$ in the soils of Fukushima Prefecture: preliminary reconstruction of ${ }^{131} \mathrm{I}$ deposition related to the accident at Fukushima Daiichi Nuclear Power Plant (FDNPP), J. Environ. Radioact. 139, 344-350.

PoghosyanA., Sturchio N. C., 2015, Temporal evolution of ${ }^{36} \mathrm{Cl}$ abundances in the Great Lakes, J. Environ. Radioact. 144, 62-68.

Povinec P. P., Liong Wee Kwong L., Kaizer J., Molnar M., Nies H., Palcsu L., Papp L., Pham M.K., JeanBaptiste P., 2016, Impact of the Fukushima accident on tritium, radiocarbon and radiocesium levels in seawater of the western North Pacific Ocean: A comparison with pre-Fukushima situation, J. Environ. Radioact., article in press, 1-11.

Raisbeck G. M., Yiou F., 1999, ${ }^{129}$ I in the oceans: origins and applications, Sci. Total Environ. 237/238, 3141.

Roux C., Le Gal La Salle C., Simonucci C., Van Meir N., Fifield L. K., ASTER Team, Diez O., Bassot S., Simler R., Bugai D., Kashparov V., Lancelot J., 2014, High ${ }^{36} \mathrm{Cl} / \mathrm{Cl}$ ratios in Chernobyl groundwater, J. Environ. Radioact. 138, 19-32.

Sakaguchi A., Kawai K., Steier P., Imanaka T., Hoshi M., Endo S., Zhumadilov K., Yamamoto M., 2010, Feasibility of using ${ }^{236} \mathrm{U}$ to reconstruct close-in fallout deposition from the Hiroshima atomic bomb, Sci. Total Environ. 408, 5392-5398.

Santos F. J., López-Gutiérrez J. M., García-León M., Schnabel Ch, Synal H. A., Suter M., 2004, Analysis of ${ }^{36} \mathrm{Cl}$ in atmospheric samples from Seville (Spain) by AMS, Nuc. Instrum. and Meth. in Phys. Res. B223/224, 501-506.

Santos F. J., López-Gutiérrez J. M., Chamizo E., García-León M., H.A. Synal, 2006, Advances on the determination of atmospheric ${ }^{129}$ I by acceleratormass spectrometry (AMS), Nuc. Instrum. and Meth. in Phys. Res. B249, 772-775.

Santos F. J., López-Gutiérrez J. M., García-León M., Synal H. A., San Miguel E. G., 2007, ${ }^{129}$ I record in a sediment core from Tinto River (Spain), Nuc. Instrum. and Meth. in Phys. Res. B259, 503-507.

Santos F.J., Gómez-Martínez I., García-León M., 2009, Radiocarbon measurement program at the Centro Nacional de Aceleradores (CNA), Spain, Radiocarbon 51, 883-889.

Schwehr K. A., Otosaka S., Merchel S., Kapland D. I., Zhang S., Xua C., Li H.-P., Ho Y.-F., Yeager C. M., Santschi P. H., ASTER Team, 2014, Speciation of iodine isotopes inside and outside of a contaminant plume at the Savannah River Site, Sci. Total Environ. 497/498, 671-678.

Skipperud L., Brown J., Fifield L. K., Oughton D. H., Salbu B., 2009, Association of plutonium with sediments from the Ob and Yenisey Rivers and Estuaries, J. Environ. Radioact. 100, 290-300.

Sookdeo A., Cornett J., Kieser W. E., 2015, Optimizing production of $\mathrm{Pb}$ beams for ${ }^{205,210} \mathrm{~Pb}$ analysis by Accelerator Mass Spectrometry, Nuc. Instrum. and Meth. in Phys. Res. B361, 450-453.

Srncik M., Steier P., Wallner G., 2011, Depth profile of ${ }^{236} \mathrm{U} /{ }^{238} \mathrm{U}$ in soil samples in La Palma, Canary Islands, J. Environ. Radioact. 102, 614-619.

Srncik M., Tims S. G., De Cesare M., Fifield L. K., 2014, First measurements of ${ }^{236} \mathrm{U}$ concentrations and ${ }^{236} \mathrm{U} /{ }^{239} \mathrm{Pu}$ isotopic ratios in a Southern Hemisphere soil far from nuclear test or reactor sites, J. Environ. Radioact. 132, 108-114.

Tierney K. M., Muir G. K. P., Cook G. T., MacKinnon G., Howe J. A., Heymans J. J., Xu S., 2016, Accumulation of Sellafield-derived radiocarbon $\left({ }^{14} \mathrm{C}\right)$ in Irish Sea and West of Scotland intertidal shells and sediments, J. Environ. Radioact. 151, 321-327.

Tosaki Y., Tase N., Sasa K., Takahashi T., Nagashima Y., 2012,Measurement of the ${ }^{36} \mathrm{Cl}$ deposition flux in central Japan: natural background levels and seasonal variability, J. Environ. Radioact. 106, 73-80.

Tumey S. J., Brown T. A., Hamilton T. E., Hillegonds D. J., 2008, Accelerator mass spectrometry of strontium-90 for homeland security, environmental monitoring and human health,Nuc. Instrum. and Meth. in Phys. Res. B266, 2242-2245.

Tuniz C., Norton G., 2008, Accelerator mass spectrometry: New trends and applications, Nuc. Instrum. and Meth. in Phys. Res. B266, 1837-1845.

United Nations Scientific Committee on the Effects of Atomic Radiation UNSCEAR, 2008. Report to the General Assembly, Annex B: Exposure of the Public and Workers of Various Sources of Radiation, vol. 1, p. 247.

Villa M., Chamizo E., López-Lora M., Kenna T. Casacuberta N., Christl M., 2016, Measurement of ${ }^{236}$ Uat the GEOTRACES East Pacific zonal transect. These Proceedings. 
Vockenhuber C., Christl M., Hofmann C., Lachner J., Müller A. M., Synal H. A., 2011, Accelerator mass spectrometry of ${ }^{236} \mathrm{U}$ at low energies, Nuc. Instrum. and Meth. in Phys. Res. B269, 3199-3203.

Wacker L., Fifield L. K., Tims S. G., 2004, Developments in AMS of ${ }^{99}$ Tc, Nuc. Instrum. and Meth. in Phys. Res. B223/224, 185-189.

Wang X., Jiang S., Dong K., He M., He G., Li Ch., Li S., Gong J., Lu L., 2010, Development of laboratory standards for AMS measurement of ${ }^{237} \mathrm{~Np}$, Nuc. Instrum. and Meth. in Phys. Res. B268, 1949-1953.

Wang Z.,Hu D., Xu H., Guo Q., 2014, ${ }^{14} \mathrm{C}$ distribution in atmospheric and aquatic environments around Qinshan nuclear power plant, China, Radiocarbon 56, 1107-1114.

\section{Acknowledgements}

Work supported by the Spanish Ministry MINECO project FIS2015-69673-P. 